\title{
Deaths and tumours among rotogravure printers exposed to toluene
}

\author{
B G Svensson, G Nise, V Englander, R Attewell, S Skerfving, T Möller
}

\begin{abstract}
A cohort of 1020 rotogravure printers exposed to toluene and employed for a minimum period of three months in eight plants during 1925-85 was studied. Air levels of toluene were available since 1943 in one plant and since 1969 in most. Based on these measurements and on present concentrations of toluene in blood and subcutaneous fat, the yearly average air levels in each plant were estimated. They reached a maximum of about $450 \mathrm{ppm}$ in the $1940 \mathrm{~s}$ and 1950 s but were only about $30 \mathrm{ppm}$ by the mid1980s. Exposure to benzene had occurred up to the beginning of the 1960s. Compared with regional rates, total mortality did not increase during the observation period 1952-86 (129 observed deaths $v 125$ expected; $S M R=1 \cdot 03$ ). There was no increase in mortality from nonmalignant diseases of the lungs, nervous system, or gastrointestinal and urinary tracts. There was no overall excess of tumours 1958-85 $(68 v 54, S M R=1 \cdot 26 ; 95 \%$ confidence interval, $\mathrm{CI}=0.95-1 \cdot 7)$. Among the specific cancers, only those of the respiratory tract were significantly increased (16 $v$ 9; $\mathrm{SMR}=1 \cdot 76, \mathrm{CI}=$ 1.03-2.9). Statistical significance was not attained, however, when only subjects with an exposure period of at least five years and a latency period of at least 10 years were considered. Further, there were no dose response relations with cumulated toluene dose (ppm years). There were no significant increases of tumours at other sites, including leukaemias/ lymphomas/myelomas.
\end{abstract}

Exposure to organic solvents has been associated with an increased risk of malignant diseases in some

Department of Occupational Medicine, University Hospital, S-221 85 Lund, Sweden

BG Svensson, G Nise, V Englander, R Attewell, S Skerfving

Southern Swedish Tumour Registry, University Hospital, S-221 85 Lund

T Möller epidemiological studies. ${ }^{12}$ The results of the studies however, are not consistent as to type of tumour andD others have failed to show an association between exposure to organic solvents and tumours. ${ }^{34}$

Most epidemiological studies of organic solvents and malignant diseases concern populations with exposure to a mixture of solvents. Thus information is needed on pure chemical species of solvents. Moreover, the studies are mostly retrospective with poor information on exposure levels. Better data are needed for investigating dose response relations.

Toluene, one of the most widely used solvents, is $\overrightarrow{8}$ part of the exposure to mixed solvents in manye occupational settings. It has a chemical structurø similar to that of benzene which is an established human carcinogen. ${ }^{5}$ The mutagenicity of toluene has been tested in several in vitro systems and the resulto have usually been negative when the purity of the toluene was certain. Animal studies have not con firmed toluene as a carcinogenic substance. ${ }^{6}$

An excess of chromosome aberrations in lympho cytes from workers exposed to toluene in rotogravuref printing industries has been reported. ${ }^{78}$ In a study among Swedish printing industry workers an excessD risk of lung cancer was found. ${ }^{9}$ Workers in roto gravure printing factories have been exposed to high concentrations of toluene, which is the dominant solvent used in this type of printing. Thus roto윽 gravure printers offer the possibility of studying the effects of a more defined exposure to an organico solvent than cohorts of workers with mixed exposures.

We report here data on mortality and tumout morbidity in a cohort of 1020 male workers with exposure to toluene. Special efforts have been made to quantify the past exposure.

Subjects studied and methods PLANTS

All nine rotogravure plants in Sweden were invited to ${ }^{\circ}$ participate. Eight (named A-H) responded positively? and were included in the study. Five plants are in two? of the major cities of Sweden. In 1985 the number of employees ranged from 11 to 231 (median 113) in the different plants (table 1). Plant $G$ has, besideso toluene, used some other solvents in their roto-0응 
Table 1 Number of cohort members and first year of rotogravure printing at the different plants

\begin{tabular}{lcl}
\hline Plant & Cohort members & $\begin{array}{l}\text { Start of } \\
\text { rotogravure printing }\end{array}$ \\
\hline A & 228 & 1920 \\
B & 74 & 1932 \\
D & 94 & 1956 \\
D & 60 & 1948 \\
F & 132 & 1961 \\
G & 231 & 1935 \\
H & 190 & \\
Total & 11 & \\
\hline
\end{tabular}

gravure printing. Rotogravure printing started between 1920 and 1961 in the eight companies.

\section{EXPOSED COHORT}

From each company's records name, date of birth, address, and date of start and end of employment were obtained for all workers who had been employed for three months or more from the time of the start of rotogravure printing in each company to 1985 (fig 1).

\section{FOLLOW UP}

Vital status was determined up to 31 December 1986 (table 2). Ten subjects $\left(1_{0}^{\circ}\right)$ were lost in follow up; seven because of insufficient information on identity. Of the subjects employed for five years or more, only two $\left(0 \cdot 4_{0}^{0}\right)$ were untraced.

Figure 2 shows the distribution of person-years by age group and calendar time for the observation period (1952-86) with respect to mortality.

\section{Mortality, causes of death, and tumour morbidity}

Death certificates were obtained for all subjects who died between 1952 and 1986. They had been coded according to the International Classification of Diseases (ICD) by the National Swedish Central Bureau of Statistics, which is responsible for the coding of all Swedish death certificates. All codes were transformed to the eighth revision of the ICD. The death certificate was based on necropsy in $71^{\circ}{ }_{0}$ of the cases.

Information on tumours (coded according to the

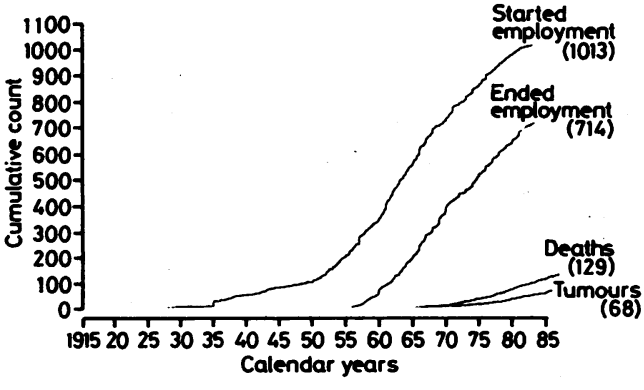

Figure 1 Accumulation during observation period of workers beginning and ending employment in all eight factories (1916-83), number of deaths observed before age 80 (1952-86), and number of malignant tumours diagnosed before age 80 (1958-85).

ICD, 7th revision) diagnosed from 1958 to 1985 was obtained from the Southern Swedish Regional and the National Swedish Tumour Registers. Each individual could have had more than one tumour registered.

\section{Reference population}

Expected mortality for the period 1952-86 was calculated using rates specific for geographical area of the factory (Stockholm, Malmö, and the county of Malmöhus), sex, calendar-year, cause of death, and five year age group. These rates were calculated from death and population counts obtained from the National Central Bureau of Statistics. Similarly, yearly morbidity rates for cancer in 1958-85 for the same areas were obtained from the Southern Swedish Regional and National Swedish Tumour Registers. Date of death or emigration were used as individual end points. Subjects with unknown vital status were not included in the comparisons. Only deaths or tumours occurring before the age of 80 have been included.

\section{Statistics}

Cause specific standardised mortality/morbidity . ratios (SMRs) and $95^{\circ}{ }_{0}$ confidence limits (CLs) were

Table 2 Vital status of the cohort of rotogravure printers exposed to toluene (1986)

\begin{tabular}{|c|c|c|c|c|}
\hline \multirow[b]{2}{*}{ Vital status } & \multicolumn{2}{|l|}{ All } & \multicolumn{2}{|c|}{$\begin{array}{l}>5 \text { years employment } \\
>10 \text { years latency }\end{array}$} \\
\hline & No & $\%$ & No & $\%$ \\
\hline $\begin{array}{l}\text { Living } \\
\text { Dead } \\
\text { Emigrated } \\
\text { Unknown (insufficient identity) }\end{array}$ & $\begin{array}{r}839 \\
131 \\
43 \\
7\end{array}$ & $\begin{array}{r}82 \\
13 \\
4 \\
1\end{array}$ & $\begin{array}{r}397 \\
92 \\
5 \\
2\end{array}$ & $\begin{array}{r}80 \\
19 \\
1 \\
-\end{array}$ \\
\hline Total & 1020 & 100 & 496 & 100 \\
\hline
\end{tabular}




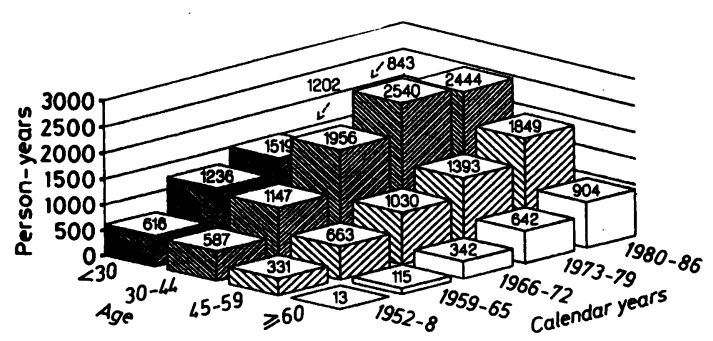

Figure 2 Distribution of 21373 person-years over age (15-80) and calendar time (1952-86) periods in cohort of 1013 workers exposed to toluene.

calculated. p Values were calculated by use of the Poisson distribution or the $\chi^{2}$ distribution if the expected values were greater than 10 . The term "significant" refers to $p<0.05$. All tests are two tailed.

\section{Exposure estimates}

TOLUENE

Exposure history has been evaluated for the six major rotogravure printing plants where toluene was the dominant solvent used.

The method used for evaluating exposure is in principle: $(a)$ visits to all the plants to get a picture of the present conditions; $(b)$ measurements of toluene concentrations in air in some of the plants; (c) determinations of toluene concentrations in biological samples (blood and subcutaneous fat) from workers in the same plants; $(d)$ collection and detailed study of all written material about the plants' occupational environments, and $(e)$ interviews with workers with a long employment period in rotogravure printing.

In plants $C, D$, and $F$ we made extensive studies of the present concentrations of toluene in air (by personal monitoring). In all we followed up the exposure during seven working weeks (C and $\mathrm{D}$ in 1983 and $F$ in 1986). The 131 time weighted samples cover more than $75^{\circ}{ }_{0}$ of the workshift. The median toluene concentration was $33 \mathrm{ppm}$ for plants $\mathrm{D}$ and $\mathrm{F}$, whereas the median for plant $\mathrm{C}$ was $7 \mathrm{ppm}$. (The rotogravure printing department of plant $\mathrm{C}$ moved into a new factory building, with modern process ventilation, in 1979.)

During environmental measurements, samples of blood and subcutaneous fat from the printers in plants $C, D$, and $F$ were collected and analysed for toluene. A significant correlation was found between the exposure during a working day and the concentration of toluene in blood directly after work. The toluene concentrations in blood before shifts increased during the working week in all plants. The toluene concentration in adipose tissue correlated with the time weighted exposure of the preceding working week. (These results have been published $\stackrel{\mathbb{P}}{?}$ separately. ${ }^{1011}$ )

As to earlier measurements, sporadic determinations of the concentrations of toluene in air had been $\frac{}{5}$ performed in all plants since 1969. Assessments $\frac{\overline{\bar{\omega}}}{\overline{0}}$ before 1975 were rare, with the exception of plant $A, \widetilde{\Phi}$ in which there are exposure data back to 1943 (four $\bigcirc$ samples in that year). During the 1950s there were 503 samples from different periods-mostly spot $\overrightarrow{0}$ samples.

For the spot sampling a "MSA combustible gas $\vec{\omega}$ indicator" (Mine Safety Appliances Company, USA) (MSA) was used. The solvent used in produc- $\frac{\mathbb{D}}{3}$ tion was used for calibration each time. The proportion of sampling done during cleaning work in the. 1950s was small: only 37 samples out of 503. For $\dot{\omega}$ cleaning work, the measured concentrations were $N$ often above the upper limit for the instrument $(1000-$ 응 $1500 \mathrm{ppm}$ ). In the written reports quantitative data are often lacking; it is just stated that high levels were found at certain work operations. (A business letter from that time mentioned a concentration of about ${ }^{\circledR}$ $5000 \mathrm{ppm}$.) Also, there were some long term samples $₫$ with a sampling time ranging from 30 to 150 minutes. Silica gel was used for solvent absorption and, after desorption with alcohol, the amount of benzene and toluene was examined by ultraviolet absorption at six $\bar{O}$ different wavelengths.

There are reports from 1969 and later where $\mathbb{D}$ colorimetric indicator tubes have been used but, $\overrightarrow{\vec{P}}$ these give only a rough estimate of exposure.

The methods used for long term measurements in the 1960s were adsorption on silica gel and analysis on an ultraviolet spectrophotometer. Gas chromatography was possibly used in 1962 , as the technique $\stackrel{\mathbb{D}}{\mathcal{D}}$ was available in the laboratory concerned from late? 1959.

From 1973 on, current sampling and analysis methods have been used: personal monitoring with charcoal tubes; desorption, mostly with carbon disulfide; and analysis on a gas chromatograph.

Comprehensive measurements have been made in $\frac{D}{O}$ all plants since 1975 . Personal monitoring by use of charcoal tubes and all glass syringes became usual. N The analyses were performed on gas chromatographs. These sampling and analysis procedures are still in common use. In some cases there are $\omega$ measurements both before and after environmental improvements.

All workers in plants $\mathrm{C}, \mathrm{D}$, and $\mathrm{F}$ have been interviewed about their working conditions, past and ${ }^{+}$ present. Some had had more than 40 years' ex- $\frac{T}{0}$ perience of rotogravure printing. The various work- $\frac{\vec{D}}{\mathbb{D}}$ ing conditions are also described in detail, both $\frac{\Omega}{\Phi}$ concerning duration and exposure level, in written $\stackrel{\mathbb{Q}}{2}$ reports since 1970. From these reports and interviews points in time for changes, of importance $O$ for the occupational hygiene in the plants, were 
noted. The ventilation systems in the plants have been improved considerably and, also, the air concentrations of toluene have decreased through an expansion of pressroom sizes, resulting in much greater volumes of diluting air.

Working procedures have been modified, with reduced exposure as a result. The handling of the printing colours is now more careful. The colour basins are covered, and the workers no longer walk around with a bucket of toluene in one hand and a bucket of printing colour in the other.

In the interviews about past conditions many printers reported that cleaning work had had to be done more often than nowadays. Also, it had to be performed carefully, since the press was expected to "shine like a sink" afterwards. From these interviews, and on the basis of our own experiences, it could be estimated that about half of one shift out of two was used for cleaning.

Earlier, there was probably significant exposure to toluene and other hydrocarbons through skin absorption. The workers were contaminated by dyes on their faces, hands, and arms. There was even, in one plant, a written recommendation to use an area with exhaust ventilation to clean skin with solvents.

Changes in the production have also been considered. Todays' journals have more pages and the printing capacity is thus much higher than earlier.

After collecting and studying all information thoroughly, the exposure evaluation began by estimating the average toluene air concentration of today in each plant. Then, by looking backwards stepwise, the exposure levels were revised whenever there was any improvement in occupational hygiene. As a basis for the estimates of the magnitude of change in the concentrations of toluene in air, there were sometimes measurements, but mostly the effect of the modification had to be estimated without such support. All measurements in all other plants were used for the estimates in a particular plant when no other information was available; the extensive measurements in plant $\mathrm{A}$ were thus of special importance.

In fig 3 a summary of the estimates of the air concentrations in the different plants over the period is presented.

\section{BENZENE}

Several of the printers interviewed mentioned the use of pure benzene during the second World War and earlier, especially during sheet printing. There was, however, no other information about using pure benzene and there was no support for this statement in written reports. The producers of printing paints in Sweden claim that they tried to eliminate benzene in the $1950 \mathrm{~s}$. The printers, however, have reported that cheaper, imported toluene was sometimes used to dilute the paints. This was probably more con-

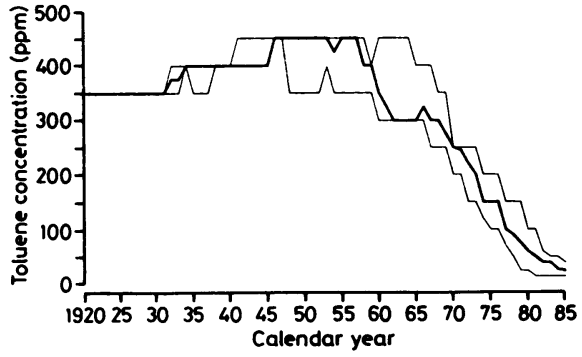

Figure 3 Median (thick line) and range (thin lines) of estimated average toluene concentration at six factories using toluene as dominant solvent between 1920 and 1985.

taminated and might be the cause of the rather high benzene concentrations in the 1960 and 1962 studies. Already then, they absorbed solvents from the exhaust air. The absorbed solvents were reused for dilution and cleaning. The benzene impurity in the toluene could therefore be present in environmental air for a long time.

Nevertheless, it is clear that before and during the second World War benzene was a component in the solvent used in rotogravure printing. Because of reports of illness and death among employees, an extensive control of the benzene content of the solvents started about 1945. For example, one of the factories producing printing inks stated that in 1952 their inks would not have contained more than $0.03^{\circ}{ }_{0}$ benzene. From 1960 and 1962 there are data on benzene in air samples in plant $A$. The mean of the measured air levels was about $3 \mathrm{ppm}$ (range 0.3-25 ppm in 1960 and $0-61 \mathrm{ppm}$ in $1962 ; 111$ spot samples in silica gel, analysed with ultraviolet spectrophotometry after eluation with ethanol or, perhaps in 1962, by gas chromatography).

\section{OTHER SOLVENTS}

In addition, other aromatic and aliphatic hydrocarbons have been used in decreasing proportions. The written reports from 1943 mention "naphta," with about $50^{\prime \prime}$ " hydrocarbons (including toluene and xylene). Later, in 1952, there was $75^{\circ}{ }^{\circ}$ aromatic hydrocarbons, mostly toluene. Since 1962 reports state $90^{\circ}$ ", toluene as a mean (range $73-98^{\circ}{ }_{0}$ ) for the solvents used in rotogravure printing. Since 1969 only toluene had been used, except in plant $G$ where substantial amounts of ethanol and ethylacetate have been used in addition to toluene.

\section{DYESTUFFS}

In rotogravure printing organic dyestuffs are used, mostly because of specific density and cover capacity requirements. These pigments are insoluble in organic solvents. The most commonly used dyestuffs are benzidine yellows, lithol reds, and phthalocya- 
Table 3 Observed (Obs) and expected (Exp) mortality 1952-86 and specific causes of death in a cohort of workers exposed to toluen $\$$

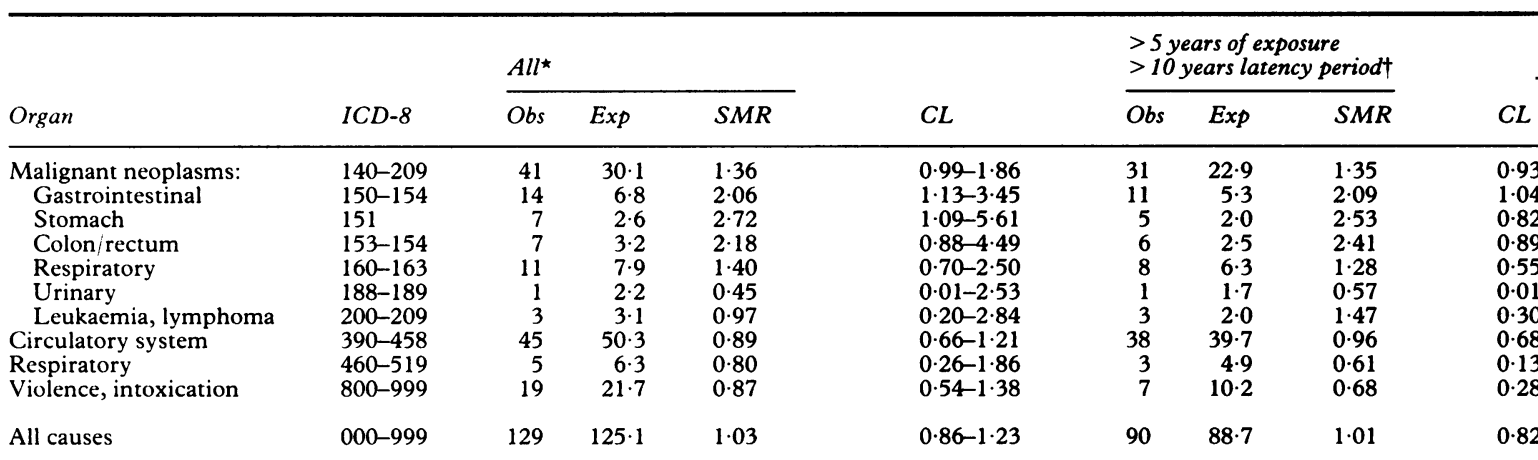

^1013 subjects, 21373 person-years under observation. $\$ 506$ subjects, 8615 person-years under observation.

nine blues. These pigments are synthetised from coal tar raw materials.

\section{Results}

\section{MORTALITY AND CAUSES OF DEATH}

In 1952-86 129 deaths were observed $v 125$ expected (SMR 1.03, fig 1, table 3); this is not significant. There was an increased risk of dying from malignant disease with SMR = 1.36; however, the lower 95\% confidence limit was 0.99 . There were statistically significant increases in deaths from tumours in the gastrointestinal tract $(S M R=2.06)$, including both stomach $(S M R=2.72)$ and colon/rectum $(S M R=$ $2 \cdot 18)$; the latter was not significant. There were no excess deaths from leukaemias or lymphomas. There was no increase in deaths from cirrhosis of the liver (observed 4, expected 3.4; SMR 1.18; not in table) or from violence or intoxication.

When only subjects employed for at least five years were considered, and a latency period of at least ten years was applied, 90 deaths were observed $v 88.7$ expected $($ SMR $=1.01$; table 3$)$. As to cause specific mortality, there was a statistically significant increase in deaths from tumours in the gastrointestinal tract $(\mathrm{SMR}=2 \cdot 09)$.
TUMOUR MORBIDITY

During 1958-85, 68 malignant tumours were registered in the cohort compared with 54 expected (SMR $\vec{c}$ $=1 \cdot 26$, fig 1 , table 4) which is not significantly different. Among the specific cancers, only those of the respiratory tract were significantly increased $\vec{\bullet}$ $(\mathrm{SMR}=1.76)$. When a minimum employment 8 period of five years and latency period of 10 years were applied, however, the increase in respiratory cancers was no longer statistically significant (nine cases observed $v$ seven expected, SMR $=1 \cdot 26$ ).

There were no associations between cumulated dose of toluene and SMRs for all tumour sites or gastrointestinal or respiratory tumours, respectively (fig 4).

\section{Discussion}

VALIDITY OF STUDY

Health examinations before starting work have been performed in some of the plants, but only during recent years. For most of the accumulated time there has been no active selection of healthy workers.

The loss in follow up is small and cannot have 윽 introduced significant bias. Diagnostic accuracy $\supset$ regarding causes of death, as well as tumours, is

Table 4 Observed (Obs) and expected (Exp) tumour morbidity 1958-85 in a cohort of workers exposed to toluene

\begin{tabular}{|c|c|c|c|c|c|c|c|c|c|}
\hline \multirow{2}{*}{$\begin{array}{l}\text { Tumour } \\
\text { Tractiorgan }\end{array}$} & \multirow[b]{2}{*}{ ICD-7 } & \multicolumn{3}{|l|}{$A l l^{\star}$} & \multirow[b]{2}{*}{$C L$} & \multicolumn{3}{|c|}{$\begin{array}{l}\geqslant 5 \text { years of exposure } \\
>10 \text { years latency period } \dagger\end{array}$} & \multirow{2}{*}{$C L_{\frac{\varrho}{\varepsilon}}^{\sigma}$} \\
\hline & & Obs & $\operatorname{Exp}$ & $S M R$ & & Obs & $\operatorname{Exp}$ & $S M R$ & \\
\hline $\begin{array}{l}\text { Gastrointestinal tract: } \\
\quad \text { Stomach: } \\
\quad \text { Colon/rectum } \\
\text { Respiratory tract } \\
\text { Urinary } \\
\text { Lymphomas/myelomas } \\
\text { Leukaemias }\end{array}$ & $\begin{array}{l}150-154 \\
151 \\
153-154 \\
160-164 \\
180-181 \\
200-203 \\
204-209\end{array}$ & $\begin{array}{r}17 \\
7 \\
9 \\
16 \\
4 \\
1 \\
3\end{array}$ & $\begin{array}{r}10 \cdot 4 \\
3 \cdot 0 \\
6 \cdot 0 \\
9 \cdot 1 \\
6 \cdot 2 \\
3 \cdot 0 \\
1 \cdot 8\end{array}$ & $\begin{array}{l}1 \cdot 63 \\
2 \cdot 34 \\
1 \cdot 49 \\
1 \cdot 76 \\
0.64 \\
0.33 \\
1.67\end{array}$ & $\begin{array}{l}0.97-2.66 \\
0.94-4.82 \\
0.68-2 \cdot 84 \\
1.03-2.91 \\
0 \cdot 18-1.65 \\
0.01-1.86 \\
0 \cdot 34-4.88\end{array}$ & $\begin{array}{r}14 \\
5 \\
8 \\
9 \\
4 \\
1 \\
3\end{array}$ & $\begin{array}{l}8 \cdot 0 \\
2 \cdot 3 \\
4 \cdot 6 \\
7 \cdot 2 \\
4 \cdot 7 \\
1 \cdot 9 \\
1 \cdot 2\end{array}$ & $\begin{array}{l}1 \cdot 75 \\
2 \cdot 18 \\
1 \cdot 74 \\
1 \cdot 26 \\
0 \cdot 85 \\
0 \cdot 52 \\
2 \cdot 54\end{array}$ & 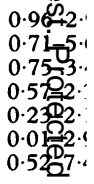 \\
\hline Total & $140-209$ & 68 & $54 \cdot 1$ & $1 \cdot 26$ & $0.98-1.60$ & 51 & $40 \cdot 1$ & $1 \cdot 27$ & $0.95<1$. \\
\hline
\end{tabular}




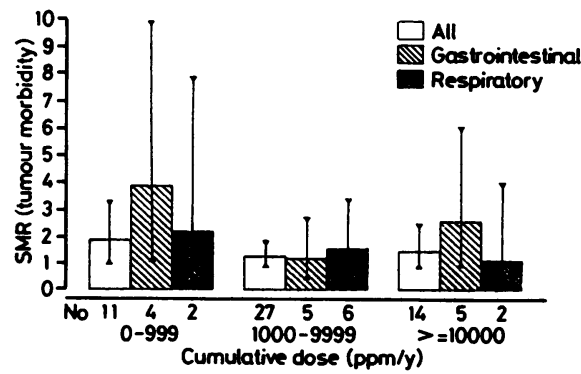

Figure $4 S M R$ for all malignant tumours (ICD 7, 140-209), gastrointestinal (150-154), and respiratory tumours (160-164) according to cumulated dose of toluene (0-999), 1000-9999, $\geqslant 10000$ ppm years) acquired up to 10 years previously. Observation time restricted to 1958-85, beginning 10 years after start of employment and up to age 80. Observed numbers of cases denoted by $N$. Thin lines indicate $95^{\circ}$ confidence intervals.

rather high: $71^{\circ}$ of the death certificates were based on necropsies and the cohort members lived near big hospitals, well equipped for diagnosing tumours.

The workers in the cohort came from plants in different parts of Sweden. The common procedure in this type of epidemiological study is to use national rates. If such rates had been used for reference the SMR for deaths from respiratory cancer would have been significantly raised to $2 \cdot 72$. About half the cohort came from plants in the Stockholm area, however, where the incidence of lung cancer is about twice that for all Sweden. ${ }^{9}$ We have thus chosen reference rates from the different regions corresponding to the locations of the plants, which must be more appropriate.

We have no information on possible confounding lifestyle factors, such as smoking and alcohol consumption, among the cohort members. As deaths from diseases related to smoking (respiratory and bladder cancers and non-malignant respiratory and cardiovascular diseases) were not increased, it is reasonable to assume that smoking habits among the exposed workers did not differ significantly from the reference population. Also, deaths from cirrhosis of the liver and violence and intoxication (often associated with excess alcohol consumption) were as expected. It thus seems to be a steady population.

The information on which estimates of the exposure levels are based is rather extensive. There are, however, limitations.

It is difficult to evaluate with any certainty the data from the MSA combustible gas indicator. That type of instrument is unstable, with low precision and specificity. Further, it only measured the instantaneous exposure level. In some protocols a range is given for the solvent concentration; sometimes a rather wide one $(200-700 \mathrm{ppm})$. This reflects the instability of the instrument and also true variations due to turbulent air movements near the press.

Some progress was made with the introduction of silica gel adsorption tubes since the sampling time could be extended to two hours but only stationary samples could be taken which did not reflect the true exposure conditions of the workers. The analytical procedure contains at least three different sources of error: (1) the desorption with ethanol, (2) the distillation, which might cause systematic errors, and (3) the ultraviolet readings. Since six different wavelengths were used for the determinations, there is a risk of spurious readings caused by impurities. These problems are not discussed in the protocols.

Since 1973 modern sampling and current analytical methods have been used. As toluene is easily desorbed and analysed, we suppose that the exposure levels since then are as reliable as those obtained today.

It is difficult to judge the overall accuracy of the estimates of the exposure to toluene. They become gradually weaker when stepping backwards, especially as to the time before 1950, when only scattered air concentration data are available. For that period, the workers' histories are almost the only information available. Nevertheless, it is probably better than a factor of two, and after 1975 considerably better.

The estimates represent the mean exposure for all the workers at each printing plant. The " 1 st printers" have no cleaning work and generally a lower exposure. The "helpers" probably have a higher exposure, since they do all the cleaning work. Also, the helpers earlier removed the just printed papers manually, when they were still warm and emitted toluene. The information on the workers tasks over time is, however, not sufficient to allow an individual exposure estimate.

Clearly, exposure to benzene occurred in the 1940 s. It certainly decreased in the 1950 s and 1960 s. In protocols from any plant benzene is not mentioned after 1969, almost certainly because the problem had been eliminated.

All the different plants in the study had a rather uniform exposure pattern. About 1960, there is a sharp fall in exposure levels. Workers employed since then have a rather low cumulated exposure to toluene and thus "dilute" the cohort, which perhaps causes an underestimate of risk among cohort members with a heavier exposure. The study of dose response relations and a case-control study within the cohort have been used to reduce this bias.

\section{MORTALITY AND TUMOURS}

We have used general population death rates for calculating the expected numbers of deaths in our cohort. It is a common experience from studies of industrial populations that this procedure results in a 
"healthy worker effect," with slightly decreased total mortality in the cohort under study. This was, however, not the case in the present study: the total number of deaths was, in fact, rather more than expected. This might indicate an increased mortality.

In the whole cohort there was a statistically significant excess of deaths from stomach cancer. Although the significance was lost when exposure and latency restrictions were applied, the number of deaths from cancer in the gastrointestinal tract was still raised. There was no clear cut dose response relation. Thus conclusions must be somewhat guarded.

In the present cohort the number of gastrointestinal cancers was higher than expected. This observation could be related to factors in the working environment but possible confounders such as major differences in food habits between the exposed and referent populations have to be considered. We have no indication of the existence of such a difference and use of regional expected rates gives this type of confounder a small margin. Toluene or other solvents have, to our knowledge, never been associated with stomach cancer. Other agents in the working environment might be of greater importance. Several of the dyestuffs used in rotogravure printing are derivatives from coal tar raw material, and some of these products have carcinogenic properties. ${ }^{12}$ The pigments, present in aerosols in the working rooms and contaminating the workers, could be of aetiological importance.

To our knowledge, there is no previous epidemiological study on workers where toluene is the dominant or only exposure. Nevertheless, toluene is often a major constituent of mixtures of organic solvents, which are common in many different occupational settings. Several epidemiological studies have suggested an association between exposure to organic solvents and malignant tumours.

Workers in the Swedish paint industry have an excess death rate in multiple myelomas. ${ }^{13}$ In casereferent studies Hodgkin's disease ${ }^{1}$ and other malignant lymphomas ${ }^{14}$ have been associated with exposure to organic solvents. These findings have not been confirmed in the present study nor in a fairly large cohort study of production workers in the United States paint and coatings manufacturing industry. ${ }^{3}$ An excess risk of colorectal (but not stomach) cancer was, however, found in that cohort but in a follow up study later it was concluded that the excesses of bowel cancer were probably not related to the job. ${ }^{4}$

In a study of proportionate mortality ratios (PMR) among spray painters in the automobile manufacturing industry ${ }^{15}$ no PMR for any cancer related cause of death achieved statistical significance. Contrary to our findings, cirrhosis of the liver, as a cause of death, was more frequent than expected among the painters.
Deaths from cancer in the respiratory tract have been raised in studies of construction and maintenance painters. ${ }^{216}$ These cancers were also more frequent than expected in our cohort, although not significantly so, when exposure and latency times were demanded. Painters working with construction and repair might have been exposed to agents other than solvents that could increase the risk for respiratory cancer including chromate pigments and asbestos.

In a Swedish register study among printing industry workers an excess risk of lung cancer was found. ${ }^{9}$ When subgroups of the original population were considered, the excess risk was mainly found among typographers and lithographers; trades not quite comparable with the rotogravure printers in the present study. A study of printers operating rotary presses showed an excess in deaths from leukaemia, renal cancer, and cirrhosis of the liver, but there was $\bigcirc$ no significant rise in lung cancer mortality. ${ }^{17}$ The excess leukaemia mortality was attributed to exposure to benzene and different pigments and dyes were suggested as possible causes to the increased renal cancer mortality.

For some periods, the workers in our cohort have been exposed to benzene, which is an established cause of acute myelocytic leukaemia. ${ }^{5}$ Also, other malignant tumours such as lymphomas and myelomas have been reported in excess after exposure to benzene. ${ }^{18}$ These tumours were, however, not increased in the present cohort. These tumours are rare; the power to detect a SMR of at least 3.0 in this study based on given expected values has been calculated to $71^{\circ}{ }_{0}$ for lymphomas and only $50 \%$ for leukaemias (one sided significance level $5^{\circ}{ }_{0}^{\circ}$ ).

With an average exposure level of $0.1 \mathrm{ppm}$ for 40 years, the risks for leukaemia have been estimated to be virtually equivalent to the background risk $^{19}$; we think that few of the cohort members would have experienced a higher cumulated exposure.

Further, the carcinogenic effects of benzene are caused by reactive metabolites. ${ }^{20}$ As the transformation of benzene to these reactive substances is inhibited by toluene, ${ }^{21}$ the simultaneous and dominant exposure to toluene might have lowered the risk of for benzene associated tumours in the cohort.

Available epidemiological data are suggestive of an association between exposure to organic solvents and development of chronic glomerulonephritis. ${ }^{22}$ There was, however, no increase in the number of deaths from renal diseases in the present cohort. Although $\overparen{D}$ long and heavy exposure to toluene and other organic solvents may cause organic brain damage ${ }^{23}$ there was no excess mortality from diseases of the nervous system. Until the beginning of the present century, printers and typesetters in Sweden had a high mortality from tuberculosis of the lung. ${ }^{24}$ The reduction of this cause of death among these trades since 
then is confirmed by the present study, as the number of deaths from non-malignant diseases of the lungs were not increased.

Most malignant tumours have a long latency time and the effects of a harmful working environment often appear late. As the major part of our cohort is still young, further follow up is necessary and the present cohort will be under continued observation.

The study was partly supported by a grant from the Swedish Work Environment Fund.

Christina Paradis and Katarina Sjöland collected and recorded the data. Margit Roos, Irma Hedlund, Margareta Liedbäck, Olle Berg, Jan Lundin, Inger Tillberg, Petter Larsten, Lars Stenström, Ella Billnor, Henry Hellberg, and Kaj Åberg helped to select cohort members.

1 Olsson $\mathrm{H}$, Brandt L. Occupational exposure to organic solvents and Hodgkin's disease in men: a case-referent study. Scand $J$ Work Environ Health 1980;6:302-5.

2 Matanoski GM, Stockwell HG, Diamond EL, Haring-Sweeney M, Joffe RD, Johnsson ML. A cohort mortality study of painters and allied tradesmen. Scand $J$ Work Environ Health 1986;12:16-21.

3 Morgan RW, Kaplan SD, Gaffey WR. A general mortality study of production workers in the paint and coatings manufacturing industry. A preliminary report. J Occup Med 1981;23:13-21.

4 Morgan RW, Claxton KW, Kaplan SD, Parsons JM, Wong O. Mortality of paint and coatings industry workers. A follow-up study. J Occup Med 1985;27:377-8.

5 International Agency for Research on Cancer. Monographs on the evaluation of carcinogenic risks of chemical to humans. Vol 29. Some industrial chemicals and dyestuffs. Geneva: IARC, 1982: 93-148.

6 World Health Organisation. Environmental health criteria 52: toluene. Geneva: WHO, 1985.

7 Funes-Cravioto F, Kolmodin-Hedman B, Lindsten J, et al. Chromosome aberrations and sister chromatid exchange in workers in chemical laboratories and a rotoprinting factory and in children of woman laboratory workers. Lancet 1977; ii: 322-5.

8 Bauchinger M, Schmid E, Dresp J, Kolin-Gerresheim J, Hauf $\mathrm{R}$, Suhr E. Chromosome changes in lymphocytes after occupational exposure to toluene. Mutat Res 1982;102: 439-45.

9 Malker HSR, Gemne G. A register-epidemiology study on cancer among Swedish printing industry workers. Arch Environ Health 1987;42:73-82.

10 Nise G, Örbaeck P. Toluene in venous blood during and after work in rotogravure printing. Int Arch Occup Environ Health 1988;60:31-5.

11 Nise G, Attewell R, Skerfving S, Örbaeck P. Elimination of toluene from venous blood and adipose tissue after occupational exposure. Br J Ind Med 1989;46:407-11.

12 International Agency for Research on Cancer. Monographs on the evaluation of carcinogenic risks of chemical to humans. Suppl 7 . Overall evaluation of carcinogenicity: an updating of IARC monographs vols 1 to 42 . Lyon: IARC, 1987.

13 Lundberg I. Mortality and cancer incidence among Swedish paint industry workers with long-term exposure to organic solvents. Scand J Work Environ Health 1986;12:108-13.

14 Hardell L, Eriksson M, Lenner P, Lundgren E. Malignant lymphoma and exposure to chemicals, especially organic solvents, chlorophenols and phenoxy acids: a case-control study. Br J Cancer 1981;43:169-76.

15 Chiazze L, Ference LD, Wolf PH. Mortality among automobile assembly workers. I. Spray painters. J Occup Med 1980;22 $520-6$.

16 Engholm G, Englund A. Cancer incidence and mortality among Swedish painters. Advances in Modern Environmental Toxicology 1982;2:173-85.

17 Paganini-Hill A, Glazer E, Henderson BE, Ross RK. Causespecific mortality among newspaper web pressmen. J Occup Med 1980;22:542-4.

18 Aksoy M. Malignancies due to occupational exposures to benzene. Am J Ind Med 1985;7:395-402.

19 Rinsky RA, Smith AB, Hornung R, et al. Benzene and leukemia. An epidemiologic risk assessment. $N$ Engl J Med 1987;316: $1044-50$.

20 Berlin M. Low level benzene exposure in Sweden: effect on blood elements and body burden of benzene. Am J Ind Med 1985;7:365-73.

21 Andrews LS, Lee EW, Witmer CM, Kocsis JJ, Snyder R. Effects of toluene on the metabolism, disposition, and hemopoietic toxicity of ${ }^{3} \mathrm{H}$-benzene. Biochem Pharmacol 1977; 26:293-300.

22 Lauwerys R, Bernard A, Viau C, Buchet J-P. Kidney disorders and hematotoxicity from organic solvent exposure. Scand $J$ Work Environ Health 1985;11,suppl 1:83-90.

23 World Health Organisation. Chronic effects of organic solvents on the central nervous system and diagnostic criteria. Copenhagen: WHO, 1985. (Environmental health series 5.)

24 Olsson L. Gamla typer och nya produktionsförhällanden. Lund: Lucifers förlag, 1986. (In Swedish.)

Accepted 6 November 1989 